\title{
VENEZUELA: HISTORIA, POLÍTICA Y LITERATURA \\ (CONVERSACIÓN CON ARTURO USLAR PIETRI)
}

POR

\author{
ANTONio López ORTEGA
}

Antonio López Ortega: En Ud. han convivido muchos personajes: el escritor, el ensayista, el hombre público. Ud. atraviesa verticalmente todo el siglo XX venezolano y ha sido testigo de sus momentos mayores y menores. Ud. ha sostenido en diferentes tribunas que el hilo democrático venezolano comienza inmediatamente después de la caída de Gómez y que ese ensayo de recuperación fue abortado por el derrocamiento del general Medina. ¿Hasta qué punto el gobierno de Medina nos hubiera podido conducir hacia una democracia moderna? ¿No llevaban los gobiernos de López Contreras y Medina el estigma del Gomecismo?

Arturo Uslar Pietri: Gómez fue el precio que pagamos los venezolanos para tener una democracia. Hemos podido comprarla a un precio más barato, es verdad, pero la compramos a ese precio y la teníamos. Cuando llegó un hombre como Eleazar López Contreras, que es uno de los hombres más extraordinarios de la historia de Venezuela, y le tocó esa chuchería que era recibir la dictadura de Gómez y desarmarla (yo viví esa época, tenía treinta años para entonces), la impresión que había en el país era que el país iba al caos, que todo aquello se había sostenido por la voluntad de Gómez que estaba arriba pero que, desaparecido Gómez, el país volvía a la anarquía desenfrenada, al caos administrativo, que iban a volver los alzamientos, los jefes y jefecitos, y que el país se perdía. López Contreras tuvo la inmensa virtud, por su carácter y por su manera de entender el momento histórico, de evitar eso, de no permitir la ruptura, de mantener las instituciones y de iniciar una transformación muy seria, muy sólida y muy sincera, de un monumento de gobierno personalista hacia una democracia. Eso lo hizo con muchísima habilidad. Y, viendo esto, uno se pone a pensar en cosas sobre las que la gente pierde la perspectiva, sobre cosas como éstas: el primer presupuesto nacional que tuvo Eleazar López Contreras a la muerte de Gómez era de 169 millones de bolívares. Óigalo bien: 169 millones de bolívares. Ud. le puede aplicar a eso todos los reajustes de poder adquisitivo que quiera. Pero es ridículo: con eso no vive hoy en día ni una universidad venezolana. Ni el Ministerio de Educación se sostiene con el doble de eso hoy en día. Pues con eso recibió Eleazar López Contreras a Venezuela y con eso la administró y la mantuvo. Y una cosa adicional muy importante: que ni López Contreras ni Medina endeudaron a Venezuela en un céntimo. Había grandes tentaciones y a un país tan rico como Venezuela no le hubiera sido difícil conseguir cualquier 
préstamo. No lo hicieron, no endeudaron a Venezuela. Establecieron una disciplina social, establecieron un inmenso voluntariado y empezaron una transformación hacia la democracia verdaderamente admirable. La reforma petrolera del año 1943 fue una de esas cosas monumentales que se han hecho en Venezuela. Y todo con un aspecto muy digno de tener en cuenta: eran hombres honestos. Yo era Secretario de la Presidencia de la República cuando terminó el proceso de negociación de la reforma, que duró como tres años y que fue muy difícil pues estábamos en plena guerra mundial, y vino el entonces presidente de la Shell en Venezuela, que era el Sr. Laudon, un hombre muy importante que después fue presidente mundial de la Shell. Laudon venía después de haber cumplido una visita a la casa matriz y yo lo recibí en Miraflores. Entonces él me vino a decir que la casa matriz estaba muy contenta por los arreglos que se habían alcanzado, que se consideraban positivos, que estaban dispuestos a trabajar dentro de las nuevas realidades y a colaborar para que el país siguiera adelante. Entonces yo le dije: "Mire, Sr. Laudon, yo espero que Ud. le comunique a la casa matriz algo que es muy importante: que esta inmensa operación, cuyo valor en dinero no es estimable y en la que está envuelta toda la riqueza petrolera venezolana (nadie sabe cuánto vale la riqueza petrolera venezolana; eso ya entra en la fábula de las cifras) se hizo sin que hubiera un céntimo para ningún funcionario público". Y él me dijo: "Dr. Uslar, yo no se los dije porque eso lo saben ellos, pero le quiero decir que eso es una cosa excepcional en el mundo». Después vino la ruptura del 18 de octubre. La ruptura del 18 de octubre fue tremenda y trágica para Venezuela. Primero porque llegó al poder una minoría inexperta, que no tenía ninguna experiencia de gobierno, con unas vagas ideas socialdemócratas en la cabeza, sin poder de ninguna especie, débiles frente a sus socios militares, débiles frente a la opinión pública, que tuvo que entrar en una carrera desenfrenada de demagogia para fabricarse un apoyo frente a los militares (quienes, después, a pesar de todo, los despacharon) y frente al país mismo. Entonces empezaron a politizar todo el país: politizaron todos los gremios, politizaron las universidades, politizaron todas las funciones públicas. $\mathrm{Y}$ todo para que hubiera bases de apoyo (con lo cual todavía estamos pagando ese pecado y lo seguiremos pagando quién sabe hasta cuándo). Eso creó una situación monstruosa en el país: empezaron a endeudar al país y cometieron errores garrafales en materia petrolera. Y entonces cuando eso fracasó, porque tenía que fracasar, los militares los desembarcaron y entramos en los diez años de dictadura de Pérez Jiménez, con todos los defectos que tuvo esa dictadura puesto que Pérez Jiménez era en gran parte hijo de esa situación y, aunque rectificó algunas cosas, no rectificó todas las que hubiera tenido que rectificar. Y así desembocamos en el 1958. Y desgraciadamente en el 58 volvió al poder Rómulo Betancourt.

Antonio López Ortega: Si veíamos una continuidad después del Gomecismo que evolucionaba muy bien tanto en López Contreras como en Medina, ¿cómo es posible que esa ruptura del 18 de octubre se haya dado, cuál fue el problema de fondo?

Arturo Uslar Pietri: Es que no había problema de fondo, es que se dio por mera sorpresa. Yo era Ministro de Relaciones Interiores cuando el 18 de octubre. Un año antes se descubrió una conspiración de sargentos que fue develada. El partido que más se rasgó las vestiduras, que más protestó y que pidió castigos ejemplares fue Acción Democrática, cuyo presidente era Rómulo Gallegos y cuyo vicepresidente era Andrés Eloy Blanco, 
ninguno de los cuales sabía una palabra del 18 de octubre. El 18 de octubre lo manejaron Betancourt, Leoni, Prieto, Barrios y Edmundo Fernández, que no era militante adeco. Eso fue una conspiración callada que no la sabía el partido. Cuando ocurrió el alzamiento la mayoría de los adecos no sabía lo que estaba pasando. Lo que tiró Betancourt, que era un hombre impaciente, fue una "parada criolla", pues se dio cuenta de que se le iba poniendo lejos la oportunidad de llegar al poder. Lejos relativamente, pues hubiera podido llegar en diez años y con un partido más maduro, más sólido y con un conocimiento más cabal de la situación del país. Por un accidente, Betancourt se enteró de que había esa conspiración militar, una conspiración por lo demás mínima. En ese momento, en el ejército de Venezuela debía haber alrededor de dos mil oficiales. Y los que estaban en la conspiración eran ciento y pico de oficiales subalternos. Y en el momento del apogeo de aquel 18 de octubre, a las cuatro de la tarde, ellos no tenían ni un cuartel en Venezuela. Lo único que tenían era el Palacio de Miraflores, la Escuela Militar y, en parte, el Cuartel San Carlos, que perdieron en la tarde. El país estaba en paz y tranquilidad y el golpe estaba fracasado. No fracasó porque Miraflores se convirtió en una trampajaula de coger a la gente más útil. A Miraflores llegó toda la gente más útil a ofrecerle su apoyo al gobierno: llegó el general López Contreras, llegó Monseñor Pellín, llegó Jóvito Villalba, llegó Alberto Ravell, llegaron los dirigentes sindicales de la época. Y a medida que llegaban los ponían presos. A mí me sacaron de Miraflores como a las cuatro de la tarde junto a Mario Briceño Iragorry, que era Presidente del Congreso (yo era Ministro del Interior). Nos llevaron entonces en un automóvil a la Escuela Militar con guardia de tropa. Y al llegar a la Escuela Militar vimos en la puerta a Carlos Delgado Chalbaud y a un grupo de oficiales. Delgado Chalbaud nos saluda muy respetuosamente y me dice: "Bueno, Dr. Uslar, yo espero que esto sea transitorio y que no vaya a ver nada que lamentar". Nos pasaron entonces adentro y nos llevaron a una habitación que daba al patio de maniobras, que era precisamente el cuarto en el que vivía Carlos Delgado Chalbaud, profesor en ese entonces de la Escuela Militar. Ahí pasamos la noche: en una cama se acostó el general López Contreras y en dos colchonetas en el suelo nos acostamos Mario Briceño Iragorry y yo. No logramos dormir mucho porque durante toda la noche los cadetes trajeron gente de los cerros y la fueron armando con armas que ni siquiera sabían manejar. Aquello era un desembarco en Normandía, una tiramentazón espantosa que nos despertaba a cada rato. Para colmo, habían cortado la luz y el agua en el Cuartel.

Entonces a las dos de la mañana tocaron la puerta (teníamos una guardia de cadetes) y entró Carlos Delgado Chalbaud muy demacrado, con una cara de fatiga y de preocupación muy grandes. Se dirigió al general López Contreras, que estaba sentado en una silla. Y entonces le digo yo: “¿Cómo está la situación, Delgado?” Y me contesta: "Está flotante, Doctor, la policía está matando mucha gente en la calle". "Eso es lo malo de estas cosas dice él-, que cuando no se dan en media hora se convierten en una tragedia". Entonces le dije yo, que estaba en mis peores momentos de furia: "Esa es la responsabilidad de los hombres que hacen estas cosas, Delgado". "Bueno sí, Doctor - me dijo-, pero ya está hecho". Entonces se dirige al general Lópezy le dice: "General, se impone una mediación. ¿Ud. no quisiera llamar al embajador de Estados Unidos para que sirva de mediador y para que nosotros podamos entregarnos?" Entonces el general se queda pensativo y dice: "Yo no puedo hacer eso. Eso se prestaría a muchas interpretaciones. Pero Ud. sí lo puede 
hacer. Llame a su pariente el doctor Oscar Augusto Machado, un hombre respetable, y dígale que lo haga". Delgado se queda pensando y dice: "Esa es una buena idea. Voy a hacerlo". Y se fue. Entonces el general López me dijo: "Esta gente está ida. Aquí vamos a salir ya". Yo había estado registrando el cuarto y encontré un revólver cargado, que era un revólver de Carlos Delgado. Y entonces me dijo el general López: "Métalo debajo del colchón que con eso nos vamos a ir". Y a eso de las cinco de las mañana llegó el avioncito de Maracay (se había pronunciado Maracay). Y ahí quedamos presos. Al general López lo sacaron desterrado.

Antonio López Ortega: ¿Cree Ud. que esta ruptura institucional de la Ud. habla corresponde a las ansias de cierta clase política?

Arturo Uslar Pietri: Yo he analizado eso en un pequeño libro mío llamado Golpe y Estado en Venezuela. Todo eso está narrado allí. Todo responde a una ambición de Betancourt. Betancourt sintió que se le alejaba la posibilidad de llegar al poder por medios pacíficos, descubrió la conexión con la conspiración militar y se lanzó a la aventura. Pero se lanzó de una manera muy taimada, sin comprometer al partido. De modo que si la cosa no funcionaba ellos eran los culpables y el partido se podía salvar.

Antonio López Ortega: ¿Estas ansias políticas no significaron para el país más de diez años de parálisis?

Arturo Uslar Pietri: No de parálisis. El país sencillamente se detuvo. Un país que venía por un camino muy maduro y muy claro, sabiendo lo que podía hacer y lo que no podía hacer (porque si algo teníamos claro era lo que podíamos y lo que no podíamos hacer), se disparó hacia una serie de ensayos locos de populismo utópico, de disparates socialdemócratas, que es lo que todavía hoy pagamos.

Antonio López Ortega: ¿Por qué no se recupera el rumbo a partir de la caída de Pérez Jiménez?

Arturo Uslar Pietri: Porque volvió Rómulo Betancourt al poder. Si a la caída de Pérez Jiménez hubiera venido Wolfgang Larrazábal al poder o hubiera venido COPEI al poder, las cosas hubieran sido distintas. Pero quien vino fue el hombre del 18 de octubre.

Antonio López Ortega: Elegido por la mayoría del país.

Arturo Uslar Pietri: ¡Claro! Betancourt le ganó a Larrazábal por un porcentaje relativamente pequeño. Porque Wolfgang Larrazábal no era un político. Wolfgang Larrazábal era un hombre muy bueno - todos lo conocemos- pero no tenía una visión política. Wolfgang Larrazábal lo que ha debido hacer no era convocar elecciones presidenciales, lo que a mi parecer era un disparate. El ha debido convocar elecciones de Asamblea Constituyente. Y esa Asamblea Constituyente hubiera legitimado al gobierno provisional y hubiera aprobado una constitución. Y luego, de acuerdo con esa nueva constitución, se hubiera procedido a la elección del Presidente de la República. No hubiera sido Rómulo Betancourt. 
Antonio López Ortega: ¿Podemos hablar de una cultura propiamente venezolana, de un sentimiento de pertenencia?

Arturo Uslar Pietri: Si entendemos por venezolanidad la concepción de la existencia de un conjunto humano caracterizado que se llama Venezuela y que, a su vez, caracteriza a quienes la componen, indudablemente podemos hablar de venezolanidad. Existe un ser y un sentimiento de comunidad nacional. Desde cuándo existe ese sentimiento, pues ese es otro problema. Cómo se ha formado, pues eso es otra cosa que habría que ver. Yo creo que ese concepto de nacionalidad está muy estrechamente vinculado con el proceso de la independencia y que es de allí que arranca. Si nuestro proceso de independencia hubiera sido distinto, posiblemente el concepto que tendríamos los venezolanos de la nacionalidad también sería distinto. Si hubiéramos tenido, por ejemplo, una independencia como la que tuvieron en Ecuador o como la que tuvieron en Chile o en Argentina, tendríamos un concepto distinto. Pero la guerra de independencia en Venezuela se caracterizó por rasgos muy peculiares. Uno fue el desproporcionado papel que Venezuela tuvo en el proceso de independencia de la América Latina. En 1810 Venezuela tenía setecientos mil habitantes y un circulante de setecientos mil pesos. Era todo lo que tenía el país. Y ese paisito, que ni siquiera era un virreinato, que apenas era una modesta capitanía general, toma el liderazgo del proceso de independencia de la América del Sur y lo lleva a término. Es una cosa verdaderamente milagrosa, increíble. Por más que uno trate de explicarlo no se encuentran explicaciones. ¿Con qué base podían aquellos hombres hacer eso? ¿Qué tenían detrás? Pues, nada. Lo hicieron puramente a base de personalidad. Salió un grupo de hombres como Miranda, como Bolívar, como Sucre, como Bello, como Páez ... hombres increíbles, ¿verdad? Y esos hombres crearon de la nada un hecho nacional que desbordó las fronteras de Venezuela y se proyectó en un hecho continental. Yo recuerdo mucho la primera vez que yo llegué a Bolivia, que fue, precisamente, en un viaje con el general Medina. Yo era entonces Ministro de Hacienda y lo acompañaba en visita oficial. Y llegamos a La Paz. El general Medina se enfermó y tuve yo que reemplazarlo en representación de la misión en un homenaje que hacía el Congreso. Cuando yo entré a la sala del Congreso en La Paz, vi que había dos grandes retratos que dominaban la sala. Eran dos venezolanos: Bolívar y Sucre. Dos venezolanos en la frontera de la Argentina, en la vertiente atlántica, con toda la América del Sur por detrás ... Bueno, eso es una cosa descomunal. Cuando yo vi aquello pensé, "Qué curioso, cómo ese paisito de setecientos mil habitantes, que quedó reducido casi a la mitad, pudo hacer aquella hazaña increíble y mantenerla durante quince años de guerra continua". Yo creo que de allí arranca el sentimiento nacional de los venezolanos. Buscarlo más atrás sería muy difícil en realidad. No tenía por qué haberlo. Además, Venezuela fue una entidad política dentro del imperio español que se constituyó muy tardíamente. Cuando vino en realidad a crearse lo que podríamos llamar la base geográfica y humana de la Venezuela actual, fue treinta años antes de la Independencia, en 1777, cuando Carlos III dio la Real Cédula de unificación de la Capitanía General y de la Gobernación. Escasamente treinta años antes de la independencia. En esos treinta años se pudo crear una vinculación entre los habitantes de la Nueva Andalucía y los que habían dependido del Virreinato de la Nueva Granada, entre los habitantes de los Andes venezolanos y la gente de los Llanos. De modo que fue el proceso de la independencia, con todas sus peculiaridades, el que dio la base para la creación de ese sentimiento. Mentalmente, esa 
proyección de inmensa realización conjunta hizo posible el surgimiento de ese sentimiento nacional. Sentimiento que posteriormente se vio fortalecido por la concepción que esos hombres tuvieron desde un primer momento: una concepción indudablemente americana. Es muy poco lo que se dice de Venezuela dentro de la literatura de estos dirigentes. Ellos siempre hablan de Colombia. Colombia es una creación venezolana, es una idea de Miranda que retoma Bolívar en 1810 con el propósito de crear una república a partir del Virreinato de Nueva Granada, de Venezuela y del Ecuador. Y esa república se llamaría Colombia. La independencia venezolana comienza por salirse de Venezuela, por concebir desde un primer momento una dimensión continental. Eso es muy importante y esa herencia la tenemos. Y esa es la base del sentimiento nacional del venezolano. Esa idea de que fuimos una gente extraordinaria que hicimos una inmensa hazaña colectiva, incomparable con la de ningún otro país latinoamericano, está en la raíz de nuestro sentimiento nacional. $\mathrm{Y}$ por lo tanto, en el fondo de nosotros mismos, estamos llamados a hacer cosas muy importantes.

Antonio López Ortega: ¿Por qué esa hazaña inicial no ha tenido continuidad?

Arturo Uslar Pietri: No ha podido tener continuidad porque el país se arruinó. La tragedia de Venezuela es la de ser un país que reveló una capacidad de acción y pensamiento gigantesca en esa hora temprana de 1810. Pero aquel movimiento inicial fue tan desproporcionado para lo que era el país que el país perdió una tercera parte de su población en la guerra de independencia. Y no sólo por muertes sino también por migraciones. El país quedó en la ruina más grande. Y después de eso, ese país arruinado, empobrecido, se separa de la Gran Colombia en 1830 y entra en un período de reconstrución muy lento y muy difícil. Y es que siempre hubo la sensación - y esto es muy importante- de que habíamos caído. Era muy curioso: como teníamos esa visión de grandeza continental de lo que habían hecho los venezolanos, nos parecía que nos habíamos reducido a unos términos muy mezquinos. Y desde esos términos mezquinos todo nos parecía pequeño e indigno. $\mathrm{Y}$ entonces allí empezaron a surgir los caudillismos, las pugnas internas, el federalismo, un siglo de guerras civiles que casi acaban con el país, que lo que hacían era empobrecerlo cada vez más y que, por lo tanto, hacían más lejana esa visión inicial. Fíjese Ud. qué cosa más curiosa: a lo largo de todo el siglo XIX hay siempre la idea de que nosotros tuvimos una grandeza y caímos de ella. Y esa grandeza fue la independencia. Cuando Guzmán Blanco intenta en los veinte años de su predominio darle un nuevo rumbo al país y sacarlo del atolladero en el que lo había situado la Guerra Federal y toda la descomposición del siglo XIX, ¿cómo llama él eso? Lo llama la Regeneración. Fíjese qué curioso: había algo que regenerar, algo muy bueno que había estado allá pero que se había echado a perder y que había que regenerar. Luego, cuando viene Castro, éste llama a su campaña la Restauración. Y Gómez llama a lo suyo la Rehabilitación Nacional. De modo que lo que había era el fantasma aquel de 1810: vamos a restituir al país que hizo la hazaña de 1810. Es muy importante esa concepción que se han mantenido en el subconsciente del venezolano. 
Antonio López Ortega: ¿Cree Ud. que existan hoy rasgos o signos que nos emparenten con ese momento?

Arturo Uslar Pietri: Nos emparentan muchas cosas. Una de ellas es la manía de ver en grande, que también nos ha llevado a veces a cometer grandes disparates. Toda esa idea de la "gran Venezuela" responde un poco en el subconsciente al deseo de volver a esa cosa que se frustró. Es decir, hicimos la independencia de la América del Sur pero luego caímos en la ruina, en la división y en el atraso. Entonces ahora - nos decimos constantemente-iremos a una empresa nueva que nos vuelva a poner en ese protagonismo y nos permita realizar cosas equivalentes. Eso está en la mente del venezolano y ese es el gran sentimiento nacional.

Antonio López Ortega: ¿Pero no cree Ud. que también se maneja un tópico de opinión que asegura que el venezolano es conformista, que no se plantea grandes empresas, que es más bien perezoso?

Arturo Uslar Pietri: Esa opinión trata de buscar explicaciones al por qué no se pudo seguir siendo lo mismo, trata de buscar las causas de por qué caímos. El libro de Pocaterra es muy revelador: se llama Memorias de un venezolano de la decadencia. Nuevamente la idea recurrente de que estábamos en una grandeza y nos vinimos abajo. Todo entra en ese esquema. Es muy curioso. Todo ha estado signado por ese desequilibrio, por ese cambio de dimensión. No supimos redimensionarnos, no pudimos redimensionarnos. En lugar de haber tenido sensatez para limitarnos a una realidad que era la que teníamos y ver qué hacíamos con ella (y al comienzo pareció que lo íbamos a hacer: los períodos de Páez, Soublette y Vargas parecían prometerlo), nos dejamos llevar por esa idea fija de reconstruir la Gran Colombia. Era imposible que llegáramos a algo sensato.

Antonio López Ortega: Ud. ha hablado de una gesta heroica colectiva. ¿No podría admitirse más bien que ese punto álgido de la venezolanidad de comienzos del siglo XIX responde a individualidades más que a designios colectivos?

Arturo Uslar Pietri: Individualidades hay en todas partes. ¿Por qué Venezuela, que era la más pobre de las provincias del Imperio español, la más atrasada (Venezuela vino a tener una imprenta prácticamente dos años antes de la independecia cuando en México la hubo desde el siglo XVII, Venezuela vino a tener una universidad veinticinco años antes de la indepedencia cuando en México y en el Perú las había desde hacía dos siglos) ... por qué ese paisito tan pobre, $\tan$ pequeño, $\tan$ mal integrado, de repente produce ese grupo de hombres. Uno se pone a pensar en la vieja Caracas, en la Caracas de 1810, que era una pequeña ciudad de cuarenta mil habitantes, y que cabía exactamente entre La Pastora y el río Guaire y entre lo que es hoy el Nuevo Circo y el comienzo de Catia, y dentro de esa vieja Caracas había lo que Arístides Rojas llamaba el "cuadrilátero histórico", que era sencillamente las cuatro o seis manzanas en torno a la plaza Bolívar ... Bueno, Ud. se pone a ver y en ese ámbito nace Miranda, nace Bolívar, nace Bello, nace Roscio, nace Sucre, nace Simón Rodríguez, nace Urdaneta, nace Monagas. Es una floración de individualidades extraordinarias, desproporcionada. Y eso le dio mucho a la historia de Venezuela y eso es lo que nos hizo uno poco sobrerrealistas. Hemos tenido dificultad para resignarnos a 
reconocer la realidad. ¿Qué podemos hacer con la realidad? Siempre tenemos ese trasfondo mágico de que somos capaces de otras cosas.

Antonio López Ortega: ¿La nacionalidad se ha visto entonces arrastrada por la utopía, por el sueño?

Arturo Uslar Pietri: Sí ... El proyecto irrealista, la "Gran Venezuela" ... Creímos que con el dinero petrolero nos convertiríamos en la gran potencia industrial de América. Y por qué no, verdad, si más pobres y atrasados nos convertimos en los libertadores de América. La respuesta es que produjimos unos hombres excepcionales y que después no los produjimos.

Antonio López Ortega: ¿Ud. cree que ya no hay venezolanos excepcionales?

Arturo Uslar Pietri: Yo sí creo que los hay. Claro que hay gente de primera clase. Hemos hecho, eso sí, todo lo posible para que no los haya. Tenemos una educación pésima. En lugar de tener una educación para producir dirigentes hemos tenido una educación con un rasero bajísimo, como si lo que quisiéramos producir fueran mediocridades. Pero sí tenemos hombres importantes en Venezuela, y en todos los campos. $\mathrm{Y}$ los seguimos produciendo. Pero no tenemos una educación para valorizarlos, no tenemos una educación para conseguir los mejores.

Antonio López Ortega: El sueño nos ha llevado a veces a episodios de grandeza pero también a episodios de fatalidad.

Arturo Uslar Pietri: Y de fracaso ...

Antonio López Ortega: ¿El mismo impulso histórico?

Arturo Uslar Pietri: El mismo impulso porque sacamos mal las cuentas. Aquello se debió en gran parte no a circunstancias nacionales, que no las había en aquel momento, sino a otras circunstancias que yo no me atrevo a analizar en este momento y que produjeron una confluencia de personalidades excepcionales. Trate de entender esto: Páez fue una personalidad excepcional. ¿Por qué un peón ganadero de fines del siglo XVIII se convierte en José Antonio Páez? ¿Por qué un pequeño burgués, un patiquín de Cumaná, de fines del siglo XVIII, se convierte en el Mariscal de Ayacucho? Hay una cantidad de interrogantes muy difíciles de contestar.

Antonio López Ortega: La coyuntura tampoco parece explicarlo. La coyuntura de ciudades pequeñas, de información limitada, de rango político inferior, no explican esos resortes que de pronto surgieron ...

Arturo Uslar Pietri: Y luego para colmo surge Bolívar. Bolívar es una figura gigantesca, una de las grandes figuras de la humanidad. Es desproporcionado que un paisito de ese tamaño haya dado un hombre de la dimensión de Bolívar. El cálculo de probabilidades no favorecía tal posibilidad. Bolívar es comparable a cualquiera de los grandes hombres de la humanidad. Y eso lo tenemos nosotros en el subconsciente. 
Antonio López Ortega: ¿Pero lo tenemos como un elemento más bien paralizante?

Arturo Uslar Pietri: Puede que sea paralizante pero puede que no lo sea. Yo recuerdo que cuando yo era muchacho había un dicho que yo creo que ya no se dice: si a uno lo pisaban uno respondía "más abajo pisó Bolívar". Eso significa mucho. Es un reconocimiento de que había una grandeza innata en aquel hombre que no necesitaba estar montado sobre nadie, que estaba en él.

Antonio López Ortega: Hemos hecho un largo recorrido desde 1810 hasta nuestros días. ¿Cómo cree Ud. que se ha comportado el discurso cultural para tratar de reflejar esa historia con tantas sacudidas? ¿Ha emulado lo cultural lo que hemos vivido en el terreno de lo social y de lo histórico?

Arturo Uslar Pietri: En el terreno de la cultura en Venezuela habría muchas cosas que decir. Yo creo que una de las grandes cosas que el país tiene que plantearse en este momento de dificultades y de reajustes es qué hacer con la cultura y para qué la queremos. Porque en torno a esto hay mucha distorsión y mucho disparate. Habría que hacer una reflexión fácil de hacer. En los cincuenta años corridos entre 1890 y 1940 Venezuela tiene un florecimiento cultural extraordinario. En esos años salen los hombres de la generación de El Cojo, sale Díaz Rodríguez, sale Pedro Emilio Coll, sale Eduardo Blanco, sale José Gil Fortoul, José Rafael Pocaterra, Rómulo Gallegos, Enrique Bernardo Núñez, Guillermo Meneses, Teresa de la Parra ... Si Ud. se va al terreno de la música sale la escuela del maestro Sojo y todo ese grupo de músicos notables del período. Y si Ud. se dirige al terreno de las artes plásticas surge la Escuela de Caracas y surgen Reverón, Monasterios, Soto, Alejandro Otero, Narváez. Bueno, jen esa época no había política cultural del Gobierno! Es un hecho. Yo me acuerdo cuando el pobre Francisco Narváez consiguió una pensioncita de cien bolívares y se fue a París. ¡No había política cultural! En cambio en los cincuenta años siguientes, el país entró en el despilfarro más loco de política cultural que haya habido y se creó una inmensa burocratización de la cultura. Ahora bien, los resultados no han sido correspondientes. Si Ud. compara las dos mitades del siglo, en la segunda hay una bajada.

Antonio López Ortega: ¿Pero tenemos acaso la distancia para apreciar lo más reciente?

Arturo Uslar Pietri: ¿Y la teníamos para saber quién era Reverón, para saber quién era Rómulo Gallegos? ¡Claro que nos dábamos cuenta de quiénes eran! Este es un tema de reflexión obligado. La cultura venezolana debe reflexionar sobre sí misma para corregir errores muy graves y peligrosos.

Antonio López Ortega: Ud. plantea un paradoja terrible, pues la inversión mayor de Estado se ha hecho precisamente en esta segunda mitad de siglo.

Arturo Uslar Pietri: Por eso afirmo que se ha hecho una cosa errónea. Se ha hecho del creador cultural un burócrata. Aquí cualquiera que escriba un libro de poemas tiene derecho a un sueldo o a una edición del Estado. Cuando yo publiqué mi primer libro, Barrabás y otros relatos, lo publiqué con mil bolívares que consiguió mi pobre padre. Todas estas dificultades producían una virtud: hacía difícil y exigente el ejercicio. Para 
que un libro se publicara tenía que ser muy bueno. Si no lo era, no había la menor posibilidad. Y eso, claro, servía de estímulo para que la gente diera lo más de sí que pudiera. Y se dio esa gran floración intelectual. Los facilismos son negativos. La política cultural en Venezuela hay que revisarla a fondo. Hay que tener un gran cuidado con la cultura, pues la cultura es una entidad sumamente delicada que puede pervertirse fácilmente por una mala dirección. De modo que lo ideal sería que estuviera lo menos dirigida posible, que se le diera mucho campo a la espontaneidad, a lo que da ella de sí. Toda política cultural tiene dos vertientes: una es la difusión cultural y otra es la creación cultural. Y no hay que confundir las dos cosas. Yo creo que el Estado tiene que hacer un gran papel en la difusión cultural. Lo ideal sería que la Orquesta Sinfónica de Boston fuera a San Fernando de Apure y ofreciera una semana de conciertos, que se hicieran exposiciones maravillosas a las que todo el país tuviera acceso, que se hicieran ediciones baratas de todos los grandes libros de la literatura de nuestra lengua y de las traducciones más importantes. Lo que gaste el Estado venezolano en difusión cultural estará siempre justificado. Ahora bien, en la creación cultural hay que ser muy cuidadoso. Históricamente hablando, no ha habido nunca un gran creador literario que haya sido un niño mimado del Estado. Uno podría justificar hasta a los artistas plásticos que trabajaban a la sombra de reyes y soberanos. Pero a los escritores no. ¿Quién pensionaba al Dante? ¿Quién pensionaba a Bocaccio? ¿Quién pensionaba a Cervantes? ¿Quién pensionaba a Shakespeare? Se trabajaba más bien en reacción a una situación social, en una actitud crítica, correctiva y ejemplarizante. En la medida en que el Estado entra a burocratizar la cultura, probablemente está matando un resorte muy importante de la vida creativa cultural. En ese campo habría que ser muy cauteloso, muy prudente.

Antonio López Ortega: ¿No presupone esa actitud que en lo masivo reside la mayor de las realizaciones? ¿No pasa lo mismo en educación?

Arturo Uslar Pietri: Es evidente que sí. La educación creyó que el ideal era que ni un solo niño venezolano dejara de ir a una escuela mediocre. Yo siempre he dicho una barbaridad y la voy a repetir: si a mí se me aparece el arcángel Gabriel y me obliga a escoger entre darle una educación de primera clase a la mitad de la población venezolana y darle una educación mediocre a toda la población venezolana, pues yo escojo la primera. La mitad de la población venezolana, o la tercera parte, con una educación de primera clase saca a Venezuela adelante. Mientras que una educación mediocre nos va a mantener en el fondo indefinidamente.

Antonio López Ortega: ¿Está Ud. admitiendo que la democracia ha sacrificado la cantidad por la calidad?

Arturo Uslar Pietri: ¡Claro que ha sacrificado la cantidad por la calidad! Se llega a niveles absurdos. Ud. habrá visto el informe que publicó recientemente la UNESCO sobre los niveles de educación en el mundo entero. Venezuela está entre los últimos niveles de capacidad discernitiva, de asimilación de lecturas, junto a Zimbabue y otros países pobres de Africa. El informe demuestra que la educación venezolana es una de las más caras y de las más ineficientes del mundo. Eso es muy grave. 
Antonio López Ortega: Vuelvo al tema cultural. En esta pléyade de escritores que Ud. enumeraba de la primera mitad del siglo se siente un interés profundo por conocer a fondo el país. Uno se asoma a la novelística de Gallegos, o uno se asoma a su misma cuentística, y es impresionante destacar el énfasis en rescatar las creencias profundas del hombre venezolano. Allí están retratados el campesino, los mitos populares, las leyendas ... Y eso es una cosa que uno ve en sintonía con otras obras. Ahora bien, ¿qué situación específica hacía que el discurso literario se interesara por valores más bien telúricos, por esas superficies iniciales sobre las que se podían edificar monumentos mayores?

Arturo Uslar Pietri: Porque había un estado general muy entendido y muy común en el que la gente tenía la sensación de que la literatura venezolana no había reflejado el país ni se había ocupado de él. Es decir, había tenido un discurso ajeno al país, un discurso neorromántico, un discurso costumbrista, y que era necesario ir más adentro.

Antonio López Ortega: Y esa era la tradición del siglo XIX: el romanticismo, el costumbrismo.

Arturo Uslar Pietri: ¡María de Jorge Isaacs! Eso era lo que estaba en el fondo. Y el costumbrismo, claro. Gallegos, por ejemplo, a pesar de todo, no va más allá de describir las grandes cuadros de ambiente. Pero los que veníamos detrás teníamos la sensación muy clara de que teníamos que ir más adentro, de que teníamos que buscar al venezolano, y de que teníamos que buscarlo y entenderlo en su condición elemental o en su complejidad. Por eso escribo yo Las lanzas coloradas. Las lanzas coloradas es una tentativa de entender qué paso con la independencia, qué pasó con esos hombres que hicieron esa cosa, cómo vieron al país y cómo reaccionaron ante él.

Antonio López Ortega: ¿Y cuál es entonces el balance de Presentación Campos: es un balance positivo o es más bien frustrante?

Arturo Uslar Pietri: A mí no me importa el balance de Presentación Campos. ¡El de Bolívar fue positivo! Y los dos estaban en el mismo proceso.

Antonio López Ortega: Pero esa pulsión inicial de la primera mitad de siglo pareciera evaporarse luego, pareciera perder interés. Es como si el tema de penetrar en la nacionalidad careciera ya de sentido. El cúmulo de influencias foráneas de los años posteriores, para bien o para mal, orientó el discurso literario hacia otros horizontes. La pulsión de lo auténtico se extravió en función de las modas y de las escuelas.

Arturo Uslar Pietri: Pero hay un aspecto allí que vale la pena considerar. En Venezuela, a partir de un cierto momento, probablemente a partir del momento en que el Estado comienza a desempeñar un papel importante en materia cultural, desaparece la crítica.

En Venezuela hubo una crítica literaria, una crítica literaria que tenía dos niveles: el nivel superior que exponía un Semprún, crítico implacable y honesto, y el nivel bajo que en el que se movían las revistas humorísticas que se dedicaban a burlarse de los malos escritores de una manera muy cruel. Hay una tradición, visible desde Fantoches hasta $E l$ Morrocoy Azul, que consistía en tener secciones reservadas para burlarse de los malos 
poetas. Al poeta que hubiera publicado unos versos malos "le daban un baño" en Fantoches. Lo traían amarrado como si fuera un loco, le aullaban, le echaban una palangana de agua y lo obligaban a recitar alguno de aquellos versos infames. Era una cosa muy cruel pero prefiguraba la existencia de una crítica, de una valoración. Había entonces un sentido crítico que señalaba la separación entre los libros buenos y los libros que no valían nada. Y eso se borró. Hoy en día en Venezuela no hay crítica, se publican reseñas de libros o elogios. Yo no he visto decir a nadie aquí que tal libro es un libro fallido, que su propósito no se alcanza ...

Antonio López Ortega: ¿Y a qué atribuye Ud. esa actitud?

Arturo Uslar Pietri: Bueno, al amiguismo, al ambiente que se ha creado, a la gran cofradía de la cultura que se ha establecido en Venezuela que hace que la gente se calle frente a sus compañeros.

Antonio López Ortega: ¿No es ese otro signo de nuestra identidad cultural?

Arturo Uslar Pietri: No, nuestra identidad cultural es otra. Es la que se deriva de nuestra situación geográfica, de nuestras herencias históricas, del juego de valores en medio del cual hemos vivido ... Existe una identidad cultural venezolana. Ahora bien, la identidad cultural mexicana es muy fácil porque tiene un ancla muy poderosa que es el pasado indígena y el pasado colonial. Son dos grandes anclajes con los cuales el mexicano logra situar una vinculación de identidad. El caso cubano es igualmente parecido porque en el caso cubano está la presencia poderosísima del negro. Yo tuve una experiencia muy curiosa que me permitió ver esto con mucha más claridad. Cuando yo llegué a París en 1929 - yo tenía apenas veintitrés años y fue allí donde escribí Las lanzas coloradastuve la suerte de encontrarme con dos hispanoamericanos de los que fui muy amigo: Miguel Ángel Asturias y Alejo Carpentier. Nos reuníamos diariamente y nos leíamos lo que escribíamos. Allí me pude dar perfectamente cuenta de las diferencias que había entre nosotros tres, de las diferencias estrictamente culturales. Miguel Ángel Asturias venía de Guatemala; obsesionado, absorbido, dominado por la visión de lo maya, porque la presencia maya en Guatemala es avasalladora. Y él entonces se empeñó en traducir al castellano de una traducción francesa, porque él no hablaba quiché, el Popol Vuh. Y su primer libro, Leyendas de Guatemala, fue una zambullida en busca de ese pasado. Y esto yo no lo sentía, yo no podía sentir la identidad indígena. La identidad indígena en Venezuela es artificial completamente, porque el indígena no tuvo una presencia avasalladora en Venezuela. Fue una presencia más bien marginal, de tribus dispersas.

Alejo Carpentier, en cambio, se anclaba en el negro. Alejo Carpentier era hijo de un francés y de una rusa, lo cual quiere decir que la sangre no cuenta mucho. Y era cubano hasta el último poro del cuerpo. Respiraba y vivía del ambiente cubano. Para Alejo la obsesión era el negro. Y la cultura negra: los santeros, los ñáñigos, los cultos de vudú. Cosas que no significaban nada para Miguel Ángel Asturias, porque el negro no existe en Guatemala, ni tampoco para mí, porque el negro en Venezuela tampoco ha tenido una presencia avasalladora. Venezuela, en cambio, es un país de inmenso mestizaje. Por lo tanto, yo venía de un medio cultural muy distinto, muy mestizo, en el que la presencia 
española, indígena y negra están muy mezcladas, muy filtradas, muy combinadas, frente a un hombre que sentía por todos lados la presencia maya y otro que sólo se apasionaba por la presencia negra. De modo que esa experiencia me ayudó mucho a comprender el fenómeno cultural latinoamericano.

Antonio López Ortega: ¿No le parece que en nuestro caso esas nutrientes étnicas son muy equilibradas?

Arturo Uslar Pietri: ¡Claro que son equilibradas! Pero hace al mismo tiempo muy difícil la definición de una identidad.

Antonio López Ortega: Todo ese anclaje cultural del que Ud. habla apela al pasado, a la tradición. Pero siguiendo con la línea de su discurso pareciera que la identidad cultural en Venezuela no apela al pasado ...

Arturo Uslar Pietri: ¡Acuérdese de la independecncia!

Antonio López Ortega: Pero es un pasado muy reciente ...

Arturo Uslar Pietri: Sí, pero es nuestro pasado. Es la referencia a la que vamos más fácilmente. El más importante bien común cultural y moral que tenemos los venezolanos es la independencia. Que no es el caso de los cubanos: el caso de los cubanos es la realidad de la presencia negra en Cuba, que es arrodalladora. Y que no es tampoco el caso de un centroamericano como Asturias, donde lo que prevalece es lo indígena.

Antonio López Ortega: ¿Se puede hablar entonces de identidad sin tradición?

Arturo Uslar Pietri: Es que son dos cosas distintas. ¿A qué llamamos tradición: a la tradición oral, a la tradición escrita? Yo no sé que valga el folklore venezolano como riqueza cultural en comparación con la de otros países. Pero tenemos una tradición, indudablemente ...

Antonio López Ortega: ¿Una tradición política?

Arturo Uslar Pietri: Política, no. Es más correcto decir histórica. Y en Venezuela está centrada en ese fenómeno tutelar llamado la independencia que, por cierto, no tuvo ningún otro país de Hispanoamérica.

Antonio López Ortega: ¿Un proceso independentista de dos décadas puede representar una referencia de identidad tan profunda como la amalgama secular que tiene en Hispanoamérica lo indígena?

Arturo Uslar Pietri: Yo no veo por qué no. Actúan de manera distinta pero están allí. ¡Acuérdese que el Cristianismo viene de tres años de prédica de Cristo! ¡Y fijese todo lo que ha pasado desde entonces! Lo importante no es que la tradición se hunda en los siglos; lo importante es lo que uno sienta en relación con lo que le pertenece. Y esa identificación el venezolano la establece con la independencia. 
Antonio López Ortega: Su novelística es fundamentalmente histórica. ¿Hay allí una tentativa de apelar a lo histórico como máxima referencia nuestra?

Arturo Uslar Pietri: Es posible. En todo caso, es inconsciente. Yo nunca me propuse hacer novelas históricas. Y yo siempre he objetado esa calificación de novela histórica. La novela histórica es una calificación que se dio a raíz del Romanticismo, cuando empezaron a aparecer, con Walter Scott y los folletinistas franceses, novelas de tema histórico.

Antonio López Ortega: Pero fijese que es muy distinto el caso de su cuentística. En su cuentística se percibe una zambullida en "el hombre y sus circunstancias". Su cuentística está llena de elementos populares: los mitos, las leyendas, el folklore. Los personajes de sus cuentos están llenos de creencias y se ubican perfectamente en una realidad dada.

Arturo Uslar Pietri: Así es. Yo no lo hice deliberadamente. A mí lo que me ha interesado siempre es el hombre, es el ser humano ... esa maravilla compleja, misteriosa, aterradora que es el ser humano. Siempre he pensado que en lugar de fabricar un prototipo, ¿por qué no coger un ser vivo? No con el propósito de hacer un retrato de él sino de tipificar en él una condición humana. Bueno, eso lo hice con Lope de Aguirre y con la Conquista en El camino de El Dorado, eso lo hice igualmente en Oficio de difuntos, que es Gómez. Pero a mí no me interesaba hacer un retrato de Gómez, pues para eso hubiera escrito una biografía; a mí me interesaba el hombre que llegó a ser Gómez y cómo el hombre que llegó a ser Gómez se sentía Gómez y sentía al país. La isla de Robinson, en cambio, sí es una tentativa de reconstruir ese ambiente en el cual aparecen esas dos grandes figuras de Bolívar y Rodríguez con sus dos visiones americanas muy complementarias y contradictorias. Ahora bien, Ud. me preguntará por qué escribí sobre Juan de Austria y yo no lo sé. La creación literaria es muy inconsciente. Si a mí me hubieran preguntado hace veinte años que hiciera una lista de cincuenta personalidades históricas sobre las cuales me hubiera gustado escribir, nunca en la vida hubiera escogido a Juan de Austria. Quizás porque Juan de Austria tenía una visión muy externa de sí mismo: el héroe de Lepanto, el hijo natural de Carlos V, el hermanastro de Felipe II metido en una intriga palaciega ... Pero de repente, por curiosidad, me cayó en las manos una mala biografía de Juan de Austria y me di cuenta de que era uno de los personajes que había tenido uno de los más graves problemas de identidad en el mundo. Precisamente, volvemos a caer en el tema de la identidad. Al igual que los grandes arquetipos literarios del momento - Hamlet nunca sabe cuál es la realidad, Hamlet vive continuamente entre una realidad y una sobrerrealidad; Segismundo no sabe quién es él-, Juan de Austria tiene un conflicto sicológico extraordinario y apasionante $\mathrm{y}$, además, mezclado con un gran momento de la Historia universal. Y me metí a escribir una cosa corta y me salió una novela de doscientas cincuenta páginas.

Antonio López Ortega: ¿Ud. me podría decir en qué circunstancias específicas escribió "La lluvia"?

Arturo Uslar Pietri: "La lluvia" lo escribí yo para un concurso literario. Yo regresé de Europa en 1934 y la revista Elite hizo un concurso de cuentos hacia fines de 1935. Yo iba en ese entonces con mucha frecuencia a Maracay y estaba muy metido en el medio 
aragüeño. Vivía mucho la vida de los campesinos de la región y de allí salieron muchos cuentos. Era una época en la que había habido un verano muy largo. ¡Y hay que ver lo que era en aquel medio tan campesino la sequía! El hecho de que la lluvia no llegara iba creando un clima, un estado de ánimo, una situación mental y física a la espera de aquel hecho milagroso de que cayera el agua del cielo. Y entonces me dije: aquí hay un cuento. Y entonces lo escribí. Y le dieron el premio.

Antonio López Ortega: En sus años de ausencia del país o de destierro, ¿qué era lo que más extrañaba?

Arturo Uslar Pietri: Yo soy un hombre muy adaptable. Soy un buen preso y soy un buen desterrado. Yo tuve una suerte inmensa. Hay gente que ha dicho que esta especie de campaña que yo hice en contra de la situación política del país en los últimos años era una especie de viejo rencor acumulado contra los adecos. Pero eso es mentira. Yo he dicho esto y lo vuelvo a repetir: yo no soy una víctima del 18 de octubre. El 18 de octubre me quitó mi casa, me aventó del país, me desterró, me quitó los pocos bienes que tenía, me quitó una posición política ... En aquel momento aquello me pareció una catástrofe pero hoy en día me parece que fue una de las mejores cosas de mi vida. Si no hubiera habido 18 de octubre yo hubiera sido un político más en la Historia de Venezuela, yo no hubiera hecho mi obra de escritor. Eventualmente, he podido llegar a ser Presidente de la República en el muy gris catálogo de los presidentes venezolanos. Y yo creo que lo que vale de mí y lo que quedará de mí es mi obra de escritor. Y eso se lo debo al 18 de octubre. El 18 de octubre me lanzó a Nueva York con unos tres mil dólares que me prestó Alfredo Boulton. Y empecé a ver cómo me iba a ganar la vida, pues tenía una mujer y dos niños. Y en esa búsqueda, don Federico de Onís, quien era entonces Jefe del Departamento de Español de la Universidad de Columbia y a quien le dedico La visita en el tiempo, supo que yo estaba en Nueva York, me llamó y me dijo "por qué no vienes a dar unos cursos en Columbia University". Me nombró entonces "Visiting Professor" en 1946 y ahí dicté un primer curso de un año al cabo del cual me nombraron "Assistant Professor" por tres años. Yo esperaba en vano que me abrieran las puertas de Venezuela. Caí, pues, en un medio prodigioso que era el Departamento de Español de Columbia. Allí estaban hombres honorables como Federico de Onís, Tomás Navarro - uno de los más grandes filólogos de la lengua española - Fernando de los Ríos - gran figura de la política española-, Paco García Lorca, su mujer Gloria de los Ríos, hija de don Fernando, Germán Arciniegas ... una cantidad de gente de primer orden y un medio sumamente excitante que me sirvió muchísimo para reencontrarme con mi vocación de escritor y volverme a sumergir en eso.

Antonio López Ortega: Esos son los años en los que Ud. escribe El camino de El Dorado y la visión de Venezuela que de esa novela se desprende es muy frustrante. ¿Por qué, además, haber escogido un personaje como Aguirre en ese momento?

Arturo Uslar Pietri: Aguirre es un personaje muy apasionante. Aguirre es el hombre que mejor ilustra el conflicto del Conquistador, que es una cosa muy mal entendida por la gente que ve la Historia muy superficialmente. La Conquista de América fue una empresa privada. La gente piensa que fue una empresa imperial, moderna, en que un Estado moderno resuelve, por ejemplo, conquistar Africa y mandar tropas. No, así no fue la Conquista en 
América. Las tierras de América se descubrieron por casualidad pero toda la empresa de conquista la hicieron por su propia cuenta y riesgo los conquistadores ... hombres que ponían barcos, gente y dinero, y que pedían una autorización y se las daban. De diez que salían nueve no llegaban a ninguna parte. Donde mejor se ve esa situación es en los primeros veinte años, de 1492 a 1517, cuando sale la expedición a México, todo lo que fue la situación inicial en las Antillas. Allí se creó una especie de paradero de aventureros, de gente que venía buscando qué hacer. Y entonces les llegaban noticias - "mire, en tal parte hay unas tribus muy ricas"- y pedían la autorización. Y la autorización se las daban para que ellos con su dinero se embarcaran en aquella historia a ver qué pasaba. Si encontraban algo, los nombraban gobernadores y les legalizaban su situación. Así se hizo la Conquista de América. Esos hombres no eran los enviados de un poder imperial, con unas funciones delegadas, no; eran empresarios privados de una aventura. Cuando la Corona española se da cuenta de aquello y quiere empezar a ponerle orden y a incorporar aquellas posesiones a su gigantesca máquina administrativa, pues comienzan a surgir los conflictos. Surgen conflictos porque la Corona dice "no se pueden dar encomiendas" y los conquistadores piensan que sí se deben dar. Y donde ese conflicto se manifiesta de la manera más abierta y espléndida es en Lope de Aguirre y en la carta que le envía a Felipe II, que es un monumento. A mí me interesó la figura de Lope de Aguirre, me metí a buscarlo e hice la novela.

Antonio López Ortega: Esa novela hurga mucho en la pesadilla del hombre, en sus zonas oscuras.

Arturo Uslar Pietri: Claro, porque Aguirre es un personaje muy contradictorio. En primer lugar, Lope de Aguirre es un viejo. Yo tengo ochentisiete años y hay muchos octogenarios hoy en día. Pero tener cincuenta años en el siglo XVI era rarísimo. Lo normal era que se murieran entre los treinta y los cuarenta años. Lope de Aguirre se embarca en aquella expedición siendo ya un viejo y cojo. El no va con ninguna ilusión de El Dorado. El va con el viejo plan de cogerse el Perú, de sacar a la Corona española y esclavizar a los indios. Yo discutía mucho eso con Miguel Otero Silva cuando Miguel escribió su libro sobre Lope de Aguirre. "No, Miguel, eso no es así; Lope de Aguirre no es un precursor de los libertadores". Lope de Aguirre quería salir del funcionario español que le estorbaba y esclavizar a los indios a su real saber y entender. obra?

Antonio López Ortega: ¿Qué gravitación tiene la figura pública que Ud. es en su

Arturo Uslar Pietri: Yo soy un producto de mi país. Yo nací en una Venezuela pobre y rural. Viví en un medio rural hasta los dieciocho años. Estuve vinculado con gente del pueblo durante toda mi juventud. Todas mis vivencias corresponden raigalmente a lo que podríamos llamar el trasfondo del hecho venezolano. Cuando yo tenía ocho años de edad mi padre tuvo un nombramiento y nos fuimos a vivir a Maracay, donde estaba el general Gómez. Yo al general Gómez lo vi muchas veces. Aquello era inenarrable: Maracay era una aldeíta de seis mil habitantes, de cuatro calles, dos de ellas pavimentadas y el resto de tierra. El hecho más importante era que allí estaba Juan Vicente Gómez y el pequeño país venía y congregaba. El general Gómez era un campesino venezolano muy tradicional, 
con todos los vicios y virtudes del campesino tradicional: muy buen administrador, muy astuto, muy realista, muy prudente, nada impulsivo.

Antonio López Ortega: ¿Y cree Ud. que Gómez estaba consciente de todo ese esfuerzo reunificador de la diáspora del siglo XIX?

Arturo Uslar Pietri: Yo sí creo que estaba consciente. Él se ufanaba de haber acabado con las guerras civiles en Venezuela, de haber creado el Ejército, de haber pagado la deuda internacional, de haber construido las carreteras troncales ... El tenía una visión de la unidad del país. Yo fui muy amigo de dos de los hijos de Gómez: Juan Vicente y Florencio. Me acuerdo una vez que iba yo para la escuela primaria que empezaba muy temprano. Tenía que aprenderme una lección y cogí por la acera de la casa del general Gómez ya que la escuela quedaba una cuadra más allá. Venía caminando muy rápido y leyendo mi libro para refrescar la lección y de repente sentí que iba a chocar con alguien: era el general Gómez que venía por la calle con un edecán. Él se me queda viendo y me dice: "¿Y para dónde vas tú?" "Yo voy para la escuela, General". "Muy bien, estudia mucho, pues". Y siguió caminando.

Antonio López Ortega: Ud. ha atravesado verticalmente el siglo XX venezolano y éste ha sido un siglo de transformaciones para el país. Al calor de toda la reflexión histórica que Ud. ha hecho, ¿cómo ve el futuro del país?

Arturo Uslar Pietri: Yo soy optimista. Venezuela sigue siendo un país inmensamente rico, cuidado si el más rico de América Latina. Olvídese Ud. de todo lo que tiene Venezuela y piense Ud. sólo en el petróleo. En este momento, las reservas probadas de Venezuela están por el orden de los sesenta mil millones de barriles. Si Ud. pone el precio del barril a diez dólares, que es un precio ridículo, son seiscientos mil millones de dólares sobre los cuales los venezolanos nos estamos tirando los pelos y no sabemos qué hacer. Eso no lo tiene ningún país latinoamericano. Las reservas de gas no las tiene ningún país latinoamericano. De modo que si nosotros hubiéramos sacado un mínimo de experiencia sensata de los muchos disparates y locuras que hemos hecho en estos últimos diez años para no repetirlos, con toda esa inmensa reserva de riqueza que tenemos podríamos tener tiempo de empezar a hacer de verdad el país que no supimos hacer en su oportunidad. Venezuela sale adelante. Todo esto ha sido una experiencia dolorosa, costosa, ingrata, pero profundamente útil. Si los venezolanos no hemos aprendido algo de todo esto por lo que hemos pasado, esto quiere entonces decir que no tenemos remedio y que no aprenderemos nunca.

Antonio López Ortega: Ud. ha sido un perseguidor implacable de los fenómenos de corrupción en Venezuela. ¿Es acaso la corrupción un signo cultural?

Arturo Uslar Pietri: Yo no lo creo. La trampa está en el fondo de los seres humanos pero logramos dominarla por convicciones morales. En Venezuela el gran mal ha sido la corrupción a la altura de la jefatura el Estado. Cuando la cabeza del Gobierno es corrupta, ¿qué se puede esperar de lo demás? El ejemplo viene de arriba. Yo creo que el presidente Caldera va a ser cosas buenas para el país por el solo hecho de no ser un hombre corrupto, de que Miraflores no va a ser una lonja de negocios como lo fue hasta ayer. Ya sólo eso es 
un cambio gigantesco ... Volviendo a su pregunta, yo creo que el venezolano es un ser generoso, profundamente afectivo, tiene una vocación inconsciente de grandeza. El problema es que el país está viviendo una situación verdaderamente insoportable, de corrupción generalizada, de disparates administrativos que han llevado el país al foso. El ejemplo corruptor es el peor enemigo del trabajo, del esfuerzo creador. Los venezolanos, por lo demás, somos herederos de una tradición muy contraria a considerar el trabajo como virtud o como cosa deseable. Primero los españoles de la época, que tenían un gran desdén por el trabajo. Las aspiraciones del español eran las de ser hidalgo y el hidalgo no podía trabajar. Miranda pasó mucho trabajo porque su padre tenía una pulpería y eso descalificaba. Luego tenemos el caso de los indígenas. El indígena no trabajaba porque los indígenas de Venezuela y de las Antillas eran recolectores y cazadores y no tenían ningún tipo de organización social en la cual hubiera algo que se pudiera llamar trabajo. Y por ese problema, presente desde la Conquista, es que viene el negro. El negro era una fuerza de trabajo pero el trabajo para él era una maldición: la pérdida de la libertad, de la individualidad. Hubo desde el comienzo una disociación entre riqueza y trabajo: el trabajar mucho no hacía rico a nadie. Los ricos eran los que heredaban las fortunas o los que se tropezaban con una manera subrepticia de hacer dinero. Allí reside una de las grandes tareas de la educación venezolana: la revalorización del trabajo y del esfuerzo individual y del ahorro y de las virtudes creativas de una sociedad normal. La educación es el único mecanismo que nos permitirá abolir nuestra imagen contrapuesta: por un lado la imagen magnificada que proyectamos hacia atrás con Bolívar pero, por el otro, la imagen que proyectamos hacia adelante y que nos hace creer que no servimos para nada. Entre esos dos polos giramos según el temperamento y la ocasión. 